\title{
Case Study: Reviewing Methods of Assessing Community Adaptive Capacity for Jefferson County, Texas
}

\author{
Faye Anderson, Najla N. J. Al-Thani \\ Center for Advances in Water and Air Quality, Lamar University, Beaumont, Texas, USA \\ Email: andersonfaye7@gmail.com
}

Received 28 November 2015; accepted 1 March 2016; published 4 March 2016

Copyright (C) 2016 by authors and Scientific Research Publishing Inc.

This work is licensed under the Creative Commons Attribution International License (CC BY). http://creativecommons.org/licenses/by/4.0/

(c) (i) Open Access

\begin{abstract}
With the increased attention on community sustainability and resilience, different poles have developed voicing similarities and/or differences of the two concepts. This study quantifies adaptive capacity of Jefferson County, Texas, one of the coastal communities at the Gulf of Mexico having some of the worse adverse effects. Review of existing methods is presented. Analyses were conducted for the last ten years: from 2005 to 2014. Interestingly, statistical analyses showed that the County's socio-economic profile or indicators have not changed throughout the ten years, but the environmental, institutional, and infrastructure indicators have. Focusing on one location magnifies the adaptive capacity of Jefferson County, the temporal aspect of both perspectives, and the relevance of existing methods to this community with its peculiarities. Future assessments need to be based on primary data collected through participatory engagement of all stakeholders. This calls for attempts to quantify adaptive capacity using the comparatively more challenging deductive reasoning, which would allow for incorporation of more risks and thus higher readiness.
\end{abstract}

\section{Keywords}

Climate Change, Resilience, Risk, Jefferson County, Texas, Flooding, Adaptive Capacity, Upper Scale System

\section{Introduction}

For a community to thrive in a constantly changing world, it needs to have great adaptive capacity, which means overcoming the unplanned or risks. Adaptive capacity has two dimensions: adaptation and the time required for the community to respond to the stressor. Adaptation can be measured by the community's sustainability, vul- 
nerability, and/or resilience [1] [2]. Although these concepts overlap, complement each other, and sometimes are used interchangeably, they are used distinctly herein. Because of their inherent uncertainties, risk examples have progressed chronologically, sadly in a commutative manner. That is, the risks that communities attempted to protect themselves against many years ago are joined by new ones, caused by the increased complexity of modern day life and by factors that did not exist then [3]. However, all risks share the characteristics of being uncertain and having undetermined severity in terms of direct and indirect costs. These risks expose vulnerabilities at different scales and dimensions, which necessitate the community to develop resilience. Having resilience extends beyond having lesser vulnerability by incorporating anticipation, adaptation, and recovery in a timely manner in order to ensure restoration or even improvement [4]. Resilience encompasses both vulnerability and sustainability, and it is a measure of the community's adaptive capacity.

The location for this study is Jefferson County in the US state of Texas $\left(29^{\circ} 48^{\prime} 41.86\right.$ "N, $\left.94^{\circ} 21^{\prime} 32^{\prime \prime} \mathrm{W}\right)$ with elevation of $18 \mathrm{ft}$ above sea level. The county's area is 2880 square $\mathrm{km}, 116$ people per square kilometer, and twenty one percent of its area is water. It is located on the Gulf of Mexico (Figure 1). The mean annual temperature is $69^{\circ} \mathrm{F}$, and the average annual precipitation is fifty-three inches [5]-[8]. The county has a social, economic, and ecological aspect that qualifies it to be a system for adaptive capacity assessment [9]. This system faces many ecological risks, including air quality issues [10]-[13], groundwater increased contamination [14] [15], soil contamination and its subsequent vegetation destruction [16]. These risks have been in effect for a long time, which increases the vulnerability of the County in face of sudden risks.

The purpose of this study is to assess the applicability of each of the three methodologies to Jefferson County, Texas. Previous assessments of the County's adaptive capacity are: Cutter et al. [17], Reams et al. [18], NOAA's Human Dimensions [19], and SHELDUS ${ }^{\mathrm{TM}}$ [20]. Cutter et al. [17] collected six resilience parameters: ecological, social, economic, infrastructure, institutional capacity, and community competence. These parameters were represented by forty two indicators, which then were standardized using the linear min-max scaling method to zero to one value where zero value reduces resilience and one value increases resilience. After applying equal weights for each parameter, all parameters were added for each system (county in this case), in order to obtain a score named social vulnerability index (SoVI) for each county in the US. Jefferson County's SoVI came out to be in the top 20\% (high). Recurrent factors among the counties of high SoVI were race (Black) and socioeconomic status, gender, families ethnicity, immigration, rural/urban, age, nursing home residents, gendered labor, and occupation. The selected indicators expressed $74.4 \%$ of the variation in the analyzed dataset. A

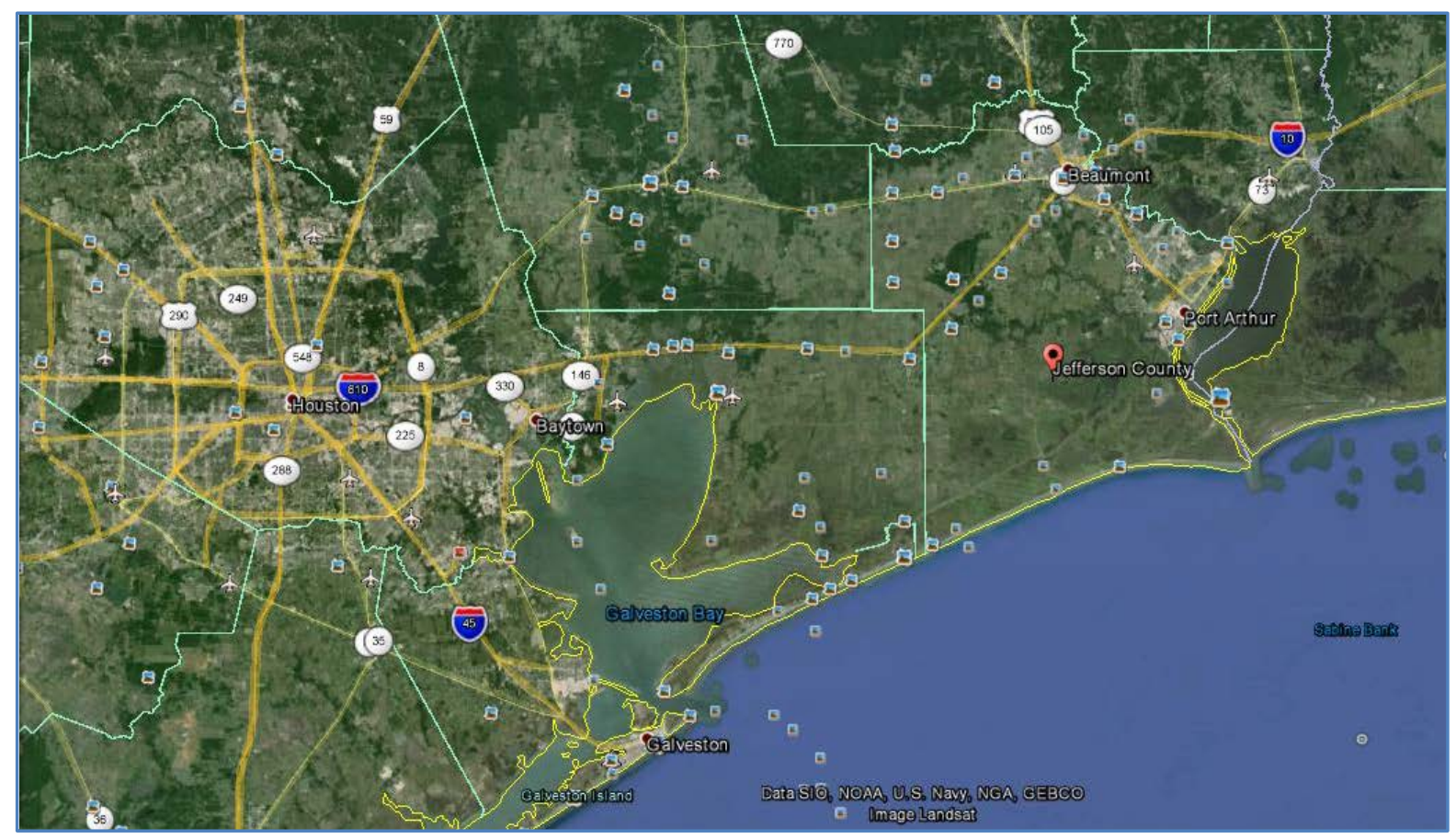

Figure 1. Location of Jefferson County to the east of Houston, Texas. 
later version of the method showed Jefferson County having a medium SoVI, where principal component analysis was used to point to the main components/indicators that account for the greatest variance within the dataset [21]. Reams et al. [18] followed the methodology of Cutter et al. [17] but with applied the method to fifty two coastal counties of the US northern Gulf of Mexico region using forty three indicators to measure community resilience represented by demographics, social capital, economic resources, local government actions, and environmental aspects. Principal component analysis was performed to derive eleven components that accounted for 76.4\% of variance of all the indicators. NOAA's Human Dimensions [19] is also based on Cutter et al.'s [17] methodology, but selected a different set of indicators in order to quantify communities' social vulnerability, gentrification pressure, sea level rise vulnerability, and fishing engagement and reliance. Last but not least, SHELDUS ${ }^{\mathrm{TM}}$ quantifies US counties' resilience against eighteen natural hazards that resulted in more than $\$ 50,000$ in damage or at least one death. SHELDUS ${ }^{\text {TM}}$ 's estimate for Jefferson County's total losses in 2005 (year when Hurricane Katrina landed) was in the range between $\$ 10$ million and $\$ 6$ billion. SHELDUS'M's estimate for Jefferson County's total losses in 2008 (year when Hurricane Ike landed) was more than \$100 million. Finally, SHELDUSTM is not free to use.

The four assessments discussed earlier provide a quantitative measurement that can help the communities and policy makers make decisions on more accurate knowledge. They are all based on the system size of county, which can be enhanced to smaller unit of analysis but with the limitation of data availability. They relied heavily on principal component analysis which necessitated standardization. These assessments relied on principal component analyses, which is a dimension reduction technique that works only if the original variables were associated. Moreover, it is based only on the mean vector and the covariance matrix of the data. Some distributions like the multivariate normal are entirely characterized by this, but others are not [22]. In addition, all of the methods were based on secondary data, which means that none of them was based on participatory action research where the residents themselves were involved and engaged in the assessment.

\section{Methods}

Data used to calculate the indicators for the last ten years from 2005 to 2014 were downloaded from the US Census Bureau [8], US Environmental Protection Agency's (EPA) Toxic Release Inventory (TRI) [10], The Center for Operational Oceanographic Products and Services (CO-OPS) [23], and Federal Emergency Management Agency Impact Reports [24]. Annual concentrations of particulate matter were calculated based on data from EPA's Air Data website [25]. Statistical analyses were conducted using R version 3.1.1. Descriptive statistics were performed using the build-in functions within the stats package [26]. Table 1 gives example of the analyzed variables.

\section{Table 1. Example analyzed indicators, their scopes and descriptions.}

\begin{tabular}{|c|c|c|}
\hline Scope & Indicator & Description \\
\hline Economic & Percent unemployed & Percentage of population ages $16+$ unemployed and looking for work \\
\hline Economic & Percent in poverty & Poverty Estimate all ages \\
\hline Economic & Percent severe housing problems & $\begin{array}{l}\text { Percentage of households with at least } 1 \text { of } 4 \text { housing problems: } \\
\text { overcrowding, high housing costs, or lack of kitchen or plumbing facilities }\end{array}$ \\
\hline Environmental & Average daily PM $2.5\left(\mu \mathrm{g} / \mathrm{m}^{3}\right)$ & $\begin{array}{l}\text { Average daily amount of fine particulate matter in micrograms per } \\
\text { cubic meter }\end{array}$ \\
\hline Environmental & Percent in drinking water violation & $\begin{array}{c}\text { Population affected by a water violation/total population } \\
\text { with public water }\end{array}$ \\
\hline Environmental & Water use (million gal/day) & Water use (fresh and saline), in million gal/day \\
\hline Environmental & Organic production & Number of organic producers \\
\hline Social & Percent non-obese & Percentage of adults that report BMI $<30$ \\
\hline Social & Percent some college & Percentage of adults age 25 - 44 with some post-secondary education \\
\hline Institutional & Hazard mitigation plan & Maintained local and federal hazard mitigation plan \\
\hline Infrastructure & Shelters & Presence of shelters and their capacity \\
\hline Infrastructure & Hospitals capacity & Number of beds per 10,000 \\
\hline
\end{tabular}




\section{Results}

Jefferson County is in the Western Gulf Coastal Plain ecoregion, also known as the Gulf Coast Prairies and Marshes ecoregion in eastern Texas and western Louisiana [5]. The highly populated areas of the County are the ones with highest inundated risk. In 2014, 14\% of the its population receive drinking water that does not meet drinking water standards including exceeding maximum contaminant levels, maximum residual disinfectant level and treatment technique violations. Other indicators of quality of life also rank low when compared to other communities in the US. Examples include 22\% adult smoking, 36\% adult obesity, and 33\% alcohol-impaired driving deaths. In addition, 57\% of children enrolled in public schools are eligible for free lunch. Figure 2 gives the trend of poverty throughout the ten years. Poverty trend has been increasing since 2011.

Annual toxic release is one of the highest in the nation. It continued to decrease from 2006 through 2011 but kept increasing in the last few years (Figure 3). To put the numbers in perspective, in 2013 total toxic release per capita in Jefferson County was twenty seven times that for the nation (Figure 4). This is due to the high concentration of refineries in a historically oil boomtown [27]. According to CO-OPS [23] sea level by Jefferson County has continued to increase and that during the ten years from 2005 to 2014, it risen by about 5 centimeters [23]. On the positive side, the percentage of population with post-secondary education increased from $3.2 \%$ in 2005 to $5.3 \%$ in 2014.

Percentage of the County’s population who are Hispanic increased from $13.15 \%$ in 2005 to $18.87 \%$ in 2014. Percentage of females also increased from 44.84\% in 2005 to 51.12\% in 2014. Median age decreased by half a year in the ten years. Percentage of Asians increased from 2.84\% in 2005 to 3.68\% in 2014. Population increased

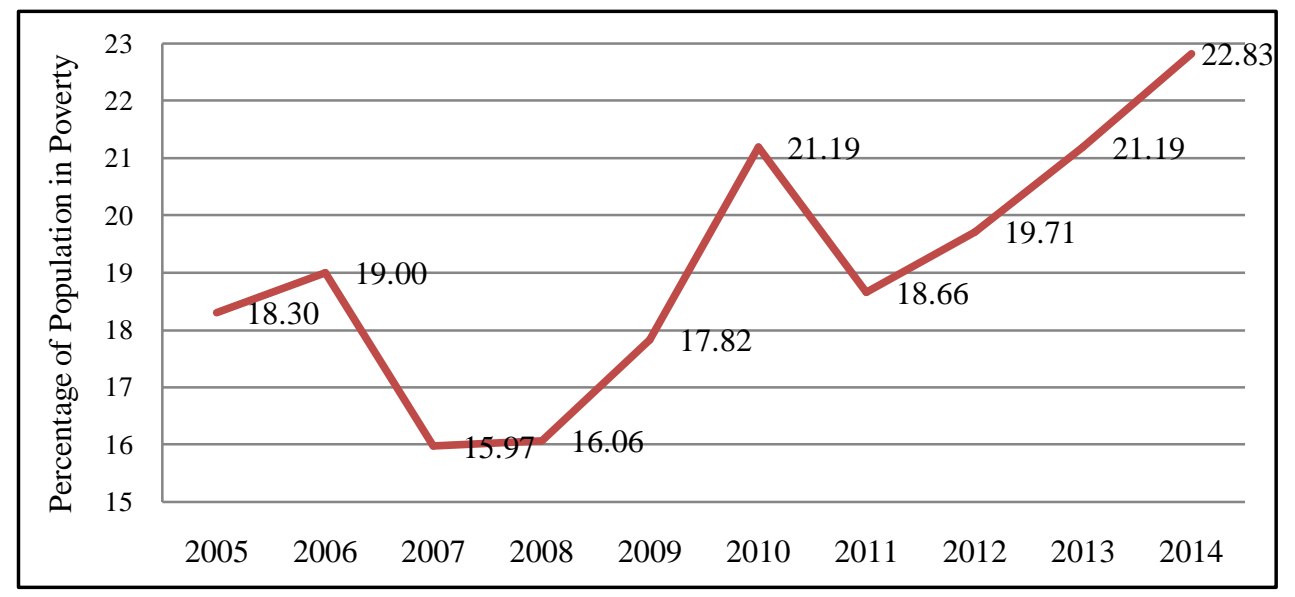

Figure 2. Temporal trend of poverty during the last decade in Jefferson County, Texas.

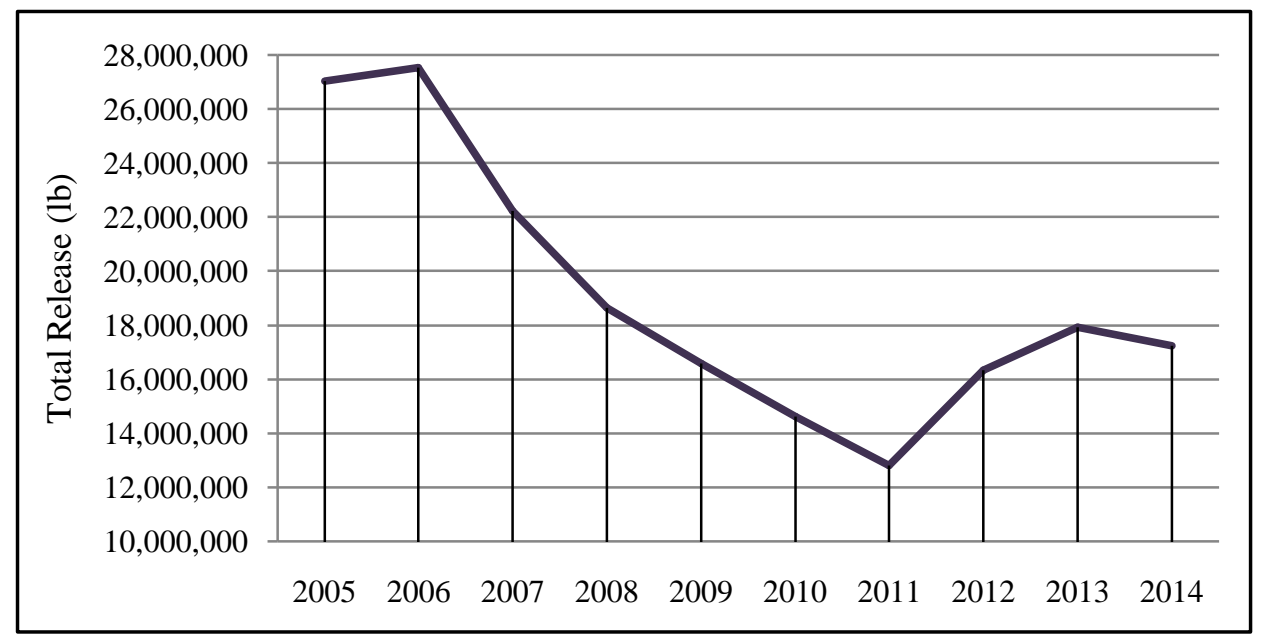

Figure 3. Annual toxic release from 2005 to 2014 in Jefferson County, Texas [10]. 


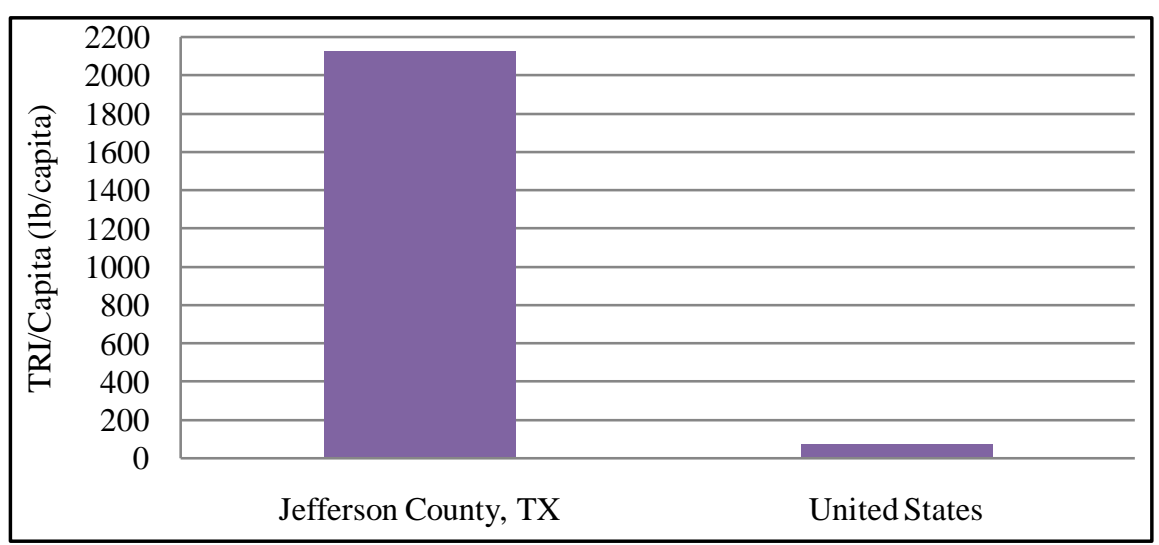

Figure 4. Annual toxic release per capita in Jefferson County and the US in 2013 [10].

only by $1.88 \%$ but change of African American's percentage was negligible ( $0.79 \%$ increase). Annual cumulative precipitation fluctuated and showed the drought risk that hit the County in 2011 (Figure 5). Records of deaths as a result of hurricanes were documented in 2005 and it was six. Percentage of the County's population who are sixty five years or older remained in the range between $12.5 \%$ and $13.5 \%$.

Pearson pair-wise correlation calculations showed few interesting associations. Percentage of Asians was strongly positively correlated with the population, poverty, and percentage of Hispanics. Percentage of Hispanics was strongly positively associated with poverty as well. There was also a somewhat strong positively association between the percentage of Native Americans and percentage of females. And there was a strong positive association between percentage of females and educational attainment. Fisher's F-test was used to test the null hypothesis of non-changing variances between the ten years socio-economic indicators. Fisher's F-test p-values were all greater than the significance level of 0.05 . Hence we could not reject the null hypothesis of equal variances. Moreover, repeated measures t-test was used to test the null hypothesis of non-changing means also for the socio-economic indicators. T-tests p-values were all greater than the significance level of 0.05 . Hence the null hypothesis of equal means could not be rejected. This means that the socio-economic profile of the county did not change throughout the decade (2005-2014). This did not apply to the environmental, institutional, and infrastructure indicators.

\section{Discussion}

Although the previously mentioned assessments [17]-[20] brought value in quantifying communities' resilience in the US, they lacked the temporal comparisons intra- and inter-counties. Analyzing the six dimensions of Jefferson County resilience over ten years provided new findings. Despite the County's exposure to three major risks: Hurricane Katrina in 2005, Hurricane Ike in 2008 and the drought of 2011, its socioeconomic profile has not changed. This means that the community's resilience score is either non-responsive to its socio-economic indicators, or the other indicators are bottlenecked by these two axes. Analyses showed the high vulnerabilities of the County, which support the latter argument. Addressing the County's vulnerabilities improves its sustainability, resilience, and adaptive capacity (Figure 6).

The available data is easily accessible. Nevertheless, it limits the types of analyses that can be conducted in order to address risks that had lower likelihood in previous years; for example bioterrorism and food deserts. The ultimate approach would be to follow a deductive approach where primary data can be collected using participatory action research. This does not dismiss the value of inductive reasoning that has been done so far but builds on it and increases our chances of accurately calculating a community's adaptive capacity [28]-[30].

\section{Conclusion}

This study evaluates the existing methods aimed at assessing the adaptive capacity of Jefferson County, Texas from 2005 to 2014. All four existing methods are based on inductive reasoning which uses existing secondary data to calculate a resilience score based on many indicators that represent axes like socioeconomic, ecological, infrastructure, institutional capacity, and community competence. Statistical analyses showed that the socioeco- 


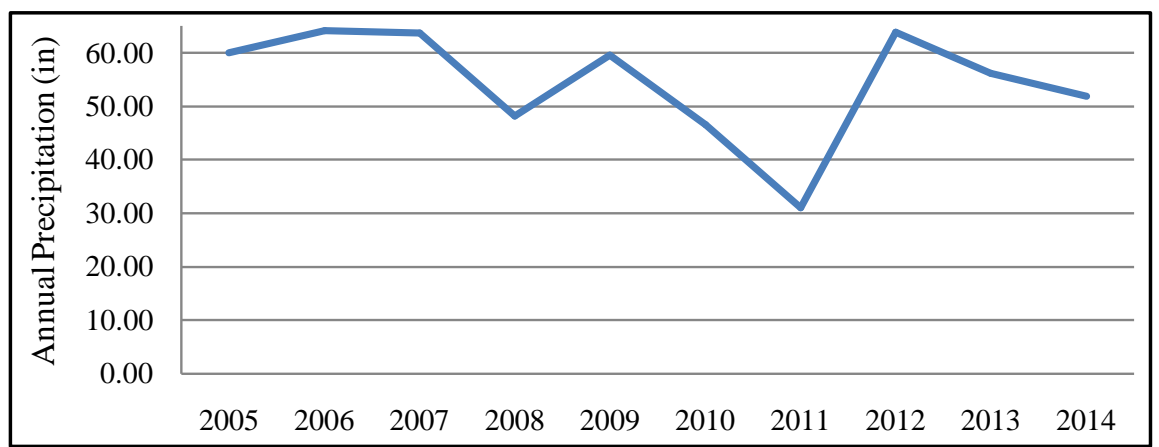

Figure 5. Annual cumulative precipitation from 2005 to 2014 in Jefferson County, Texas.

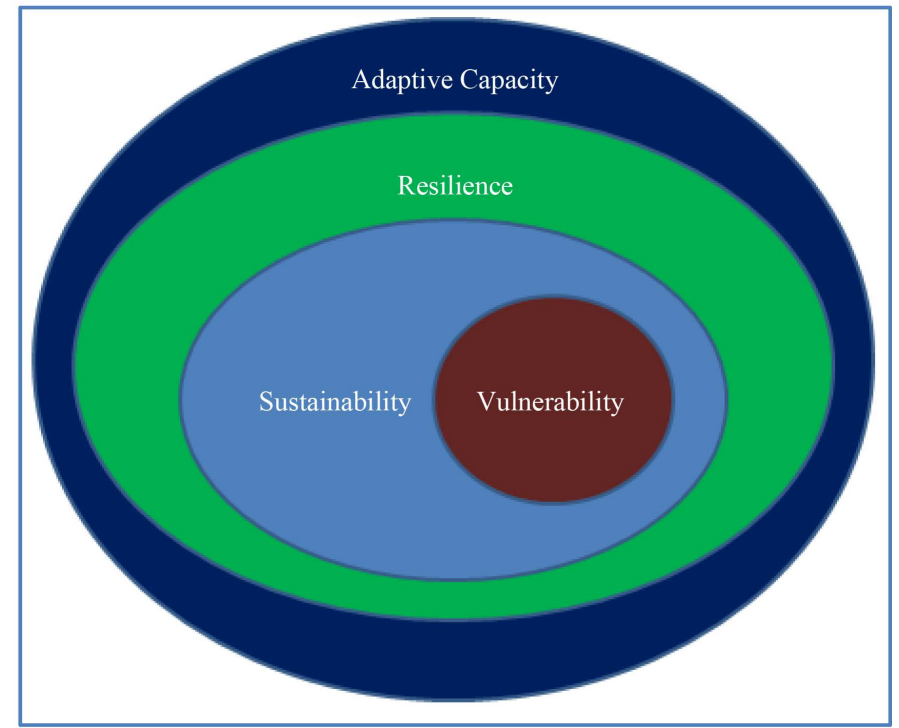

Figure 6. Vulnerability, sustainability, resilience and adaptive capacity.

nomic characteristics of Jefferson County did not significantly change throughout the ten years. However, because of its socioeconomic vulnerabilities, there is evidence that the other aspects cannot improve the County's resilience without addressing the socioeconomic issues. These results point to the need of deductive approaches to complement the findings of existing inductive approaches, using participatory action research.

\section{References}

[1] Miller, F., Osbahr, H., Boyd, E., Thomalla, F., Bharwani, S., Ziervogel, G., Walker, B., Birkmann, J., Van der Leeuw, S., Rockström, J., Hinkel, J., Downing, T., Folke, C. and Nelson, D. (2010) Resilience and Vulnerability: Complementary or Conflicting Concepts? Ecology and Society, 15, 11. http://www.ecologyandsociety.org/vol15/iss3/art11/

[2] Anderson, F. (2015) The Development of Rural Sustainability Using Participatory Action Research: A Case Study from Guatemala. Journal of Human Resource and Sustainability Studies, 3, 28-33.

[3] Britton, N.R. (2007) Managing Community Risks.

https://training.fema.gov/hiedu/docs/hram/session\%2006-1\%20-\%20handout\%20-\%20managing\%20community\%20ri sks.pdf

[4] IPCC (2012) Managing the Risks of Extreme Events and Disasters to Advance Climate Change Adaptation (SREX). Special Report of the Intergovernmental Panel on Climate Change (IPCC), IPCC Secretariat, Geneva.

[5] Anderson, F. and Al-Thani, N.N.J. (2015) Sustainability Atlas of Texas Ecoregions. (In Press)

[6] Texas State Historical Association (2015) Jefferson County. https://www.tshaonline.org/handbook/online/articles/hcj05

[7] Google (2015) Google Earth Version 7.1.5.1557. Windows 7. https://www.google.com/earth/

[8] US Census (2015) Jefferson County, Texas. http://quickfacts.census.gov/qfd/states/48/48245.html 
[9] Füssel, H.-M. and Klein, R.T.J. (2006) Climate Change Vulnerability Assessments: An Evolution of Conceptual Thinking. Climatic Change, 75, 301-329.

[10] EPA (2015) Toxic Release Inventory Explorer. http://iaspub.epa.gov/triexplorer/tri_release.chemical

[11] Anderson, F., Carson, A., Whitehead, L. and Burau, K. (2014) Spatiotemporal Analysis of the Effect of Ozone and Fine Particulate on CVD Emergency Room Visits in Harris County, Texas. Open Journal of Air Pollution, 3, 87-99. http://dx.doi.org/10.4236/ojap.2014.34009

[12] Anderson, F., Carson, A., Whitehead, L. and Burau, K. (2015) Age, Race and Gender Spatiotemporal Disparities of COPD Emergency Room Visits in Houston, Texas. Occupational Diseases and Environmental Medicine, 3, 1-9. http://dx.doi.org/10.4236/odem.2015.31001

[13] Anderson, F. and Al-Thani, N. (2015) Feasibility Study of a National Web-Based GIS Application to Assess the Risk of Pesticide Drift in the US. Journal of Geoscience and Environment Protection, 3, 20-24. http://dx.doi.org/10.4236/gep.2015.37003

[14] Anderson, F. (2014) Multivariate Geostatistical Model for Groundwater Constituents in Texas. International Journal of Geosciences, 5, 1609-1617. http://dx.doi.org/10.4236/ijg.2014.513132

[15] Mace, R.E., Davidson, S.C., Angle, E.S. and Mullican III, W.F. (2006) Aquifers of the Gulf Coast. Texas Water Development Board Report 365. https://www.twdb.texas.gov/publications/reports/numbered_reports/doc/R365/R365_Composite.pdf

[16] Goldsteen, J.B. (2010) Danger All Around: Waste Storage Crisis on the Texas and Louisiana Gulf Coast. University of Texas Press, Austin.

[17] Cutter, S.L., Boruff, B.J. and Shirley, W.L. (2003) Social Vulnerability to Environmental Hazards. Social Science Quarterly, 84, 242-261. http://dx.doi.org/10.1111/1540-6237.8402002

[18] Reams, M., Lam, N. and Baker, A. (2012) Measuring Capacity for Resilience among Coastal Counties of the US Northern Gulf of Mexico Region. American Journal of Climate Change, 1, 194-204. http://dx.doi.org/10.4236/ajcc.2012.14016

[19] NOAA (2015) Human Dimensions. http://www.st.nmfs.noaa.gov/humandimensions/social-indicators/map

[20] Hazards \& Vulnerability Research Institute (2015) SHELDUS ${ }^{\mathrm{TM}}$. http://hvri.geog.sc.edu/SHELDUS/

[21] Hazards and Vulnerability Research Institute (2013) Social Vulnerability Index for the United States—2006-10. http://webra.cas.sc.edu/hvri/products/sovi.aspx

[22] Manly, B.F.J. (1986) Multivariate Statistical Methods: A Primer. Chapman \& Hall, London.

[23] The Center for Operational Oceanographic Products and Services (CO-OPS) (2015) Center for Operational Oceanographic Products and Services. http://oceanservice.noaa.gov/facts/find-tides-currents.html

[24] Federal Emergency Management Agency (2008) Impact Reports. https://www.fema.gov/

[25] EPA (2015) AirData. http://www3.epa.gov/airdata/ad_basic.html

[26] R Core Team (2015) The R Project for Statistical Computing. https://www.r-project.org/

[27] Rohr, M. (2007) Texas Town Has Been Defined by Oil Refineries. http://www.nbcnews.com/id/21420793/ns/us_news-environment/t/texas-town-has-been-defined-oil-refineries/\#.VnNo MRUrKM8

[28] Adger, W.N., Brooks, N., Bentham, G., Agnew, M. and Eriksen, S. (2004) New Indicators of Vulnerability and Adaptive Capacity. http://ipcc-wg2.gov/njlite_download.php?id=5286

[29] Anderson, F. and Burau, K. (2015) Back to Basics: Is Civic Agriculture the Solution to Food Deserts in Texas? Open Journal of Social Sciences, 3, 82-89. http://dx.doi.org/10.4236/jss.2015.35012

[30] Redman, C.L. (2014) Should Sustainability and Resilience Be Combined or Remain Distinct Pursuits? Ecology and Society, 19, 37. http://dx.doi.org/10.5751/ES-06390-190237 